\title{
ÉL: DE MERCEDES PINTO A LUIS BUÑUEL
}

\section{Gerardo Cummings}

\author{
"A Mercedes Pinto" \\ Mercedes Pinto vive en el viento \\ de la tempestad. Con el corazón \\ frente al aire. \\ Enérgicamente sola. \\ Urgentemente viva. \\ Segura de aciertos e invocaciones. \\ Temible y amable en su trágica \\ vestidura de luz y llamas.
}

Pablo Neruda

\section{RESUMEN}

La novela de Mercedes Pinto Él es uno de los textos literarios más olvidados por expertos y académicos, pero sirvió de base para la película de Luis Buñuel del mismo nombre. Ambos textos ofrecen tópicos diferentes a explorarse, aunque la historia al principio parezca demasiado común, ya que presenta la vida matrimonial de una mujer y su esposo, y éste último sufre de una paranoia-esquizofrénica que hace peligrar la vida de la mujer, la narradora. Esta pequeña síntesis de la historia básica que comparten el texto literario y el cinematográfico no ofrece con detalle las diferencias inherentes en ambos productos de consumo intelectual. Esto es lo que se pretende en este ensayo: investigar, con detenimiento y comparativamente, las características tan similares pero tan equidistantes, estéticamente hablando, entre la novela de Pinto y la película mexicana de Buñuel.

\begin{abstract}
Mercedes Pinto's Él is one of most often overlooked Hispanic novels by critics and scholars. This text served as the basis for Luis Buñuel's 1953 film of the same name and it offers many topics of possible discussion: from spousal abuse to the role of patriarchy in the life of a Hispanic woman, it is ripe for a contemporary critical analysis. The story that both texts share can be synthesized as the trials and tribulations of a woman and her paranoid-schizophrenic husband. Pinto's work lacks a definite time and space, for it fails to state where the events take place or in what era. The absence of this information is important, for it gives the novel a very universal feel as the events could have taken place yesterday or 100 years ago to a married couple from any nation. This characteristic of the novel is just one of the many differences between Pinto's text and the film: while the first has the aforementioned characteristic, the movie cannot escape the period in which it was filmed. This is but one of the many differences between both texts to be explored in this paper from a comparative standpoint.
\end{abstract}




\section{Introducción}

En este ensayo, tras un breve esbozo de la figura de la autora de $E l$, examinaremos detalladamente el trasfondo crítico e histórico de ambos textos, el literario y el cinematográfico, para después analizar cada uno de ellos y concentrar nuestra investigación en las estructuras, tramas, personajes, temas, estilos y secuencias principales de cada texto.

Encontramos el texto literario de Pinto adecuado para nuestro estudio porque únicamente ha sido tema de discusión en los ensayos de Teresa Rodríguez Hage y Nieves Pérez Riego; ésta última, en "Él, de Mercedes Pinto: Vanguardia y paranoia", acierta a declarar que los méritos de la novela son muchos (79). El estudio biográfico y bibliográfico de Pérez Riego sobre Pinto es bastante completo, salvo unas cuestiones sin demasiada importancia. También, como declara acertadamente Paranaguá en "Pre-texto, puro texto", el cual forma parte de su estudio crítico, la única forma física en la que existe el texto de Pinto "es una reproducción facsímil de la edición original de $E ́ l$, publicada por la Viceconsejería de Cultura y Deportes del gobierno autonómico de Canarias (1989), la que nos brinda mayor información" (91). Esta dificultad para encontrar una edición, explica tal vez por qué Mercedes Pinto es, como dice Pérez Riego, "prácticamente desconocida para los estudios de la literatura de Uruguay" (71). Nosotros nos atrevemos a observar que Mercedes Pinto es, desafortunada e injustamente, desconocida en la literatura española y universal ${ }^{1}$. Pero, con el paso de los años, esta escritora se ha vuelto el foco de atención de simposios y celebraciones en su natal Tenerife, aparte de los ya mencionados estudios.

De estos, Teresa Rodríguez Hage en "Buñuel, Pinto y las fuentes del film Él”, destaca varios puntos importantes en su ensayo sobre la novela y el filme, como declarar del segundo que "sus noventa y un minutos son de los mejores de la filmografía del cineasta español" (385). Rodríguez Hage, en su artículo, presenta una extraordinaria recopilación de datos de gran valor sobre Mercedes Pinto y su novela — como información sobre la reedición de Él en México en 1948-, pero tal vez sea un análisis sobre las semejanzas entre los textos de Pinto y Buñuel lo que hace su estudio importante, aunque no completo.

De igual forma, en nuestro artículo próximo a publicarse, "Descentering Patriarchal Discourse in Buñuel and Pinto's Él', ya hemos extendido una aproximación concentrada en los niveles de silencio explayados en los textos de Pinto y Buñuel. Comprobamos que, conjuntamente, la tipología de silencio que encontramos en el texto (el silencio impuesto al "otro", el silencio auto-impuesto y el silencio terminal) encaja en el desarrollo de la historia. Esta división tripartita ejemplifica el comienzo, el desarrollo y la conclusión de la novela. En suma, al principio, "Él" silencia a la narradora; en el punto medio, la narradora y "Él" escogen el auto-silencio y, al final, después de que el esposo paranoico atenta contra la vida de la narradora y la de sus hijos, "Él" es silenciado para siempre en un manicomio.

En conjunto, estos estudios son importantes para poner en contexto el lugar crítico que experimenta hoy tan importante pero tan olvidada novela.

\section{Trasfondo histórico y crítico de ambos textos}

En 1926, a través de la Editorial de la Casa del Estudiante, se publicó en Argentina Él, equivocadamente llamada Pensamientos por algunos críticos. Su autora fue Mercedes Pinto y de Armas Clós, española de nacimiento (en las Islas Canarias para ser precisos, 1883), pero 
exiliada en México, donde murió en 1976. Pinto, aparte de Él, publicó otros trabajos literarios posteriores: una novela titulada Ella y varias obras teatrales tales como Un señor cualquiera, Mujer, Silencio y El alma grande del pequeño Juan.

La crítica y biografía sobre Mercedes Pinto, aunque casi inexistente, no es difícil de rastrear, como ya se ha expuesto en la parte introductoria de este capítulo. Su vida y obra también han sido presentadas magistralmente por Félix Zúñiga y Héctor Argente en su artículo "Mercedes Pinto: Poetisa de espíritu rebelde", incluido en una edición especial de la revista mexicana Somos (de Editorial Televisa) ${ }^{2}$. Esta revista dedicó un número especial a Pinto, a su hija Pituka y a la dinastía de los Rojo (Rubén, Gustavo y Ana Patricia). Gustavo y Rubén Rojo son actores de la industria mexicana de cine y televisión e hijos de la autora, quienes fuesen frutos de su segundo matrimonio con el español Rubén Rojo Martín. Pero esta unión, llena de dicha y felicidad, no fue la que inspiró a Mercedes Pinto a plasmar en papel su novela; fueron sus experiencias matrimoniales con su primer esposo, el duque Juan M. de Foronda y Cubillas, las que la impulsaron a exorcizar toda esa carga traumática que llevaba consigo ${ }^{3}$. Fue ésta unión la que sirvió de génesis para la novela y para el lector es bastante claro que es una novela de experiencia muy personal, cargada de una crítica feroz y desafiante contra la sociedad y en contra del statu quo patriarcal que en ese tiempo relegaba a las mujeres al papel de madres y de compañeras incondicionales del hombre.

Él fue la primera novela de Pinto adaptada a la pantalla; Ella, la segunda. Dirigida por Valeria Sarmiento, Ella (1984) está basada en otro texto de Pinto. Este último filme le debe mucho a Buñuel, aunque la directora afirma que jamás haya visto el Él de Buñuel antes de filmar Ella. Cabe aclarar que la novela de Pinto no era la primera que Buñuel adaptaba al cine, ya que para 1953 - año en que se estrenó Él - ya había llevado al cine la novela de Michel Weber El rugido del paraíso en 1947 (llamada Gran Casino en el cine), la obra teatral de Alfonso Torrado El gran calavera en 1949, el sainete Don Quintín el amargao de Carlos Arniches y José Estremera (también conocida por cinéfilos como La hija del engaño) en 1951, Pierre et Jean de Guy de Maupassant (en cine, Una mujer sin amor (Cuando los hijos no juzgan)) también del 51, y Robinson Crusoe de Daniel Defoe (en colaboración con Phillip Ansel Roll) en 1952. El desenvolvimiento de Pinto en el cine fue mínimo. Aparte de ser madre de tres actores importantes en la historia del cine y la televisión mexicana, sólo apareció como actriz en una película y escribió el guión de otra.

Las fechas de aparición de la novela (1926) y el filme (1953) demuestran que habían transcurrido casi tres décadas entre ambos textos. Este tiempo es significativo, ya que nos indica un desinterés por el espacio temporal que será prevaleciente en Él, novela y película. El mismo Buñuel afirma en Mi último suspiro que Él "no tiene nada de mexicana. La acción podría desarrollarse en cualquier parte, pues se trata del retrato de un paranoico" (239).

El tema del abuso de poder por parte del hombre en el matrimonio que tantas veces estalla en violencia y la imposición patriarcal a la que se ha aludido son fuentes inacabables de historias para programas televisivos, obras de teatro, telenovelas, artículos de periódico, películas y novelas, en todo tipo de textos contemporáneos. Baste como ejemplo el que recientemente se haya publicado en España un libro bastante a propósito: Mi marido me pega lo normal, de Miguel Llorente Acosta (2001) ${ }^{4}$. El prólogo a este libro, realizado por Victoria Camps, nombra los tres objetivos principales que, para ella, el feminismo de principios del siglo XIX tiene pendientes; de entre estos objetivos, el más importante, según ella, y el cual sirve de trampolín para el contenido del texto, es la violencia contra las mujeres. 
El comentario crítico a la situación referida en el texto de Llorente Acosta, ya se evidenciaba en el de Pinto, publicado alrededor de ochenta años antes que Mi marido me pega lo normal. Una suerte de inspiración para el estudio de Llorente Acosta, en nuestra opinión, Él contiene en ocasiones un claro mensaje social y, en otras, semeja más un ataque personal en contra del esposo (siempre referido como "Él", con comillas, acento y la primera letra en mayúscula) por parte de la narradora femenina, la cual mantiene su anonimato desde el principio hasta el final de la novela.

El filme, por su parte, ha sido reconocido mundialmente como uno de los mejores de Buñuel, quien ha afirmado identificarse con el personaje principal masculino y ha declarado que tiene mucho de este y que Él es una de sus favoritas (Buñuel por Buñuel 79, Mi último suspiro 239, respectivamente). De igual forma, se ha comentado que hasta Jacques Lacan llegó a utilizar este filme en sus clases para demostrar uno de los grados más extremos de paranoia psicológica de los seres humanos ${ }^{5}$. El propio Paulo Antonio Paranaguá presenta en una nota la referencia textual por parte de Lacan hacia Buñuel: "Kant avec Sade", incluido en sus Écrits (Paranaguá: 89). La apreciación de los críticos de cine también es notable: David Quinlan llama a Él — junto con El bruto — uno de los más "haunting films in the early 1950s" (50).

Paranaguá, hasta estos momentos, ha sido el único crítico que ha estudiado a conciencia la película de Buñuel, con algunas menciones de paso al texto de Pinto. Por esta razón, hemos decidido analizar a continuación ambos textos, evitando los recursos analíticos a los que acudió Paranaguá, para después comparar los textos de Pinto y Buñuel, con el fin de que, al final, podamos aproximar una somera conclusión.

En resumen, los estudios individuales o combinados de los textos literarios y cinematográficos de Pinto y Buñuel aún son pocos. Pero dada la importancia que va tomando el reconsiderar el lugar histórico de ellos, expondremos nuestro estudio en las páginas siguientes.

\section{Análisis del texto literario y el cinematográfico}

Texto literario: Él, de Mercedes Pinto, originalmente publicado en Argentina por Editorial de la Casa del Estudiante en 1926, reeditado en las Islas Canarias, España, por la Viceconsejería de Cultura y Deportes del Gobierno Autonómico de Canarias en 1989.

Texto fílmico: Él (1953).

\subsection{Estructura}

La paginación del facsímil de Él suma 186 y, estructuralmente hablando, está constituida de la siguiente forma: "Aclaración" es una dedicatoria disfrazada de prólogo y "Ante-libro" es básicamente un segundo prólogo; el texto de la novela ocupa la parte central, para concluir primero con un epílogo y una opinión final. El texto en sí no presenta capítulos enumerados; en su lugar encontramos secciones, fragmentos de prosa, episodios, secuencias, eventos y párrafos de información que suman un total de 110, presentados en primera persona por una narradora homodiegética, es decir, dentro de la narración. Es interesante hacer notar que el material antes del logos oficial y los epílogos fue escrito por amigos o conocidos de la escritora, excepto "Aclaración", escrito por la autora misma. Aparte de los prólogos y epílogos que 
enmarcan el texto principal, también encontramos otros textos marco: "Invocación al dolor", al principio y "Plegaria a la luz", al final.

El primero de estos últimos marcos, "Invocación al dolor", presenta la experiencia psicológica atormentante pero familiar de la narradora. Desde un principio, queda clara la familiaridad de la narradora con su conocido guardián: "Ven acá dolor, tan injustamente tratado por los hombres; acércate a mí que tan bien te conozco y a quien tú has cuidado desde niña como a la flor preferida de tu jardín" (21). En el siguiente fragmento, se muestra qué tan vieja es esta relación:

\footnotetext{
Tú me has elejido (sic) como a una novia desde que abrí los ojos a la luz... tú me has alimentado dándome a beber en tu cáliz más áureo, las lágrimas más amargas y escitantes (sic); tú me has vestido, poniéndome la túnica que más mordiere mi carne y ciñéndome la cintura con el cilicio que más desgarrar pudiera mis entrañas; tú me has acariciado la frente con mano de hierro que taladra las sienes y pincha las células hasta hacer enloquecer; tú has estendido (sic) delante de mis ojos los más bellos telones, en donde la locura y la maldad se entretenían en presentarme la cinta cinematográfica más espantosa que mente alguna pudo concebir, y conseguiste que ese "film" aterrador se quedase grabado en mi cerebro (21).
}

Como se puede apreciar, las palabras de la narradora, tal vez proféticas, intuían que tan escabrosa narrativa haría un filme definitivamente "aterrador".

El filme, Él, con duración de 91 minutos, fue filmado en los estudios Tepeyac y en locaciones de la ciudad de México y Guanajuato del 24 de noviembre de 1952 al 27 de enero de 1953. Son contados los estudios e investigaciones en los que se analiza este filme. Entre estos, el más completo es, sin lugar a dudas, el estudio crítico de Paulo Antonio Paranaguá, Luis Buñuel Él, el cual, por ser parte de la colección de textos Paidós Películas, garantiza su calidad editorial y analítica. En su sección bibliográfica, Paranaguá incluye diecinueve artículos, reseñas y capítulos dedicados a Él, texto cinematográfico.

La estructura secuencial del filme ha sido magistralmente presentada por Paranaguá en su estudio. Este crítico no sólo acierta a dividir correctamente las secuencias de Él en 41, sino que también aporta la duración exacta de cada una de las secuencias (29-67). Ávila Dueñas, siguiendo una aproximación similar a las escenas y secuencias de Él, establece líneas similares con Paranaguá, pero mantiene diferencias en sus conclusiones: Ávila Dueñas encuentra que son 17 las secuencias importantes, pero cada una está subdividida en otras sub-secuencias. Por otro lado, la versión DVD española de la película únicamente presenta como capítulos importantes 8, los cuales son identificables como: 1) Don Francisco Galván, 2) La obsesión por Gloria, 3) Una historia de tormento, 4) El regreso a casa, 5) Las excusas de Francisco, 6) Dispuestos a todo, 7) ¿Desesperación o locura? y 8) Una nueva vida.

La novela presenta una clara estructura cerrada, de acuerdo con lo que Sharon Spencer explica en Space, Time and Structure in the Modern Novel. Según Spencer, este tipo de novelas permite únicamente un punto de vista y, consecuentemente, este está distorsionado, ya que no se exponen otros que podrían entrar en desacuerdo con el principal o entre sí (26).

La película, por otra parte, aunque al comienzo aparenta representar un punto de vista objetivo (el del espectador), en el instante en que Gloria narra acontecimientos a Luis, su ex-prometido, se origina una subjetividad que sólo puede ser ofrecida por un punto de vista: el de ella. Únicamente al final del recuento en forma de flashback ${ }^{6}$ o analepsis de la luna de miel y demás desventuras con Francisco, hasta el día en que Gloria y Luis se reencuentran, vuelve la película a presentarnos la historia desde un punto de vista narrativo que se percibe como objetivo. Sobra decir que la opinión del espectador cambia después del recuento en 
flashback de Gloria, ya que Francisco toma en cierto grado aspectos psicológicos monstruosos. Es difícil para nosotros, los espectadores, desligar la imagen del Francisco de boca de Gloria, al Francisco post-flashbacks. Por otra parte, también resulta difícil compaginar la imagen del Francisco del recuento de Gloria con el Francisco del principio del filme: apuesto, buen católico y con total control de su mundo exterior y, aparentemente, de su mundo interior.

En otras palabras, al hablar del punto de vista, nos referimos también a la focalización. En Él, en el instante en que Gloria decide contarle a Luis todo lo que ha sucedido con Francisco, nos encontramos con una narración que ha pasado a otro nivel narrativo por medio de un punto de vista distinto, una focalización diferente, menos objetiva y más subjetiva. Susana Rubio Gribble, en su tesis doctoral, presenta la siguiente cita de Edward Branigan, quien lo explica de la siguiente forma:

\footnotetext{
There must always exist in a text an underlying level of omniscient narration-that which frames but is not framed-and voyeuristic reception - that which looks but is not itself seen - which together create the fictional appearance of other levels of narration. In this sense, omniscient narration and voyeuristic reception are methodological constructs (...) Hence narration can be characterized separately by a narrator and a reader (185).
}

En el texto literario, encontramos que las primeras páginas propiamente de la novela nos exponen de inmediato la situación de la narradora vivida con su esposo, ya que es desde el segundo fragmento de la novela cuando el lector empieza a notar la paranoia de "El", quien, aunque no le hace daño a la narradora en ese fragmento, intenta estrangularla en sueños en el siguiente. La situación de la narradora sí se complica considerablemente al grado de temer por su vida, ya que siente el acecho de su marido aún al dormir. El clímax llega cuando a él lo encierran y ella y sus hijos logran esconderse donde no los encuentre, aunque llegue a salir del manicomio.

La película, por su parte, también sigue esta división tripartita: la exposición se desarrolla hasta el momento del primer flashback, en el cual empieza propiamente el conflicto que complica la historia. El clímax ocurre en la iglesia, del cual saltamos temporalmente a Colombia, donde Gloria y Raúl, casados y con un hijo, visitan a Francisco, quien está recluido en un monasterio, con lo que se ofrece, así, la resolución aparente de la historia.

Como se puede apreciar, Pinto y Buñuel seguían preceptos impuestos por los griegos para codificar la trama, ya que encontramos que ambos textos, el literario y el cinematográfico, presentan una división tripartita más un supuesto apéndice. Los dos textos empiezan con información considerada parte de la exposición de la historia, para después presentar semillas de conflicto que complican la trama. Esta complicación sigue su curso hasta llegar después al clímax y a la resolución (From Story to Movie to Critique: 134).

\subsection{Trama}

Al desmenuzar la novela, la historia gira básicamente alrededor de dos personajes centrales: "El" (siempre en comillas, y con una E mayúscula sin acento) y la narradora femenina, esposa de "El" y víctima principal de sus martirios psicológicos. La trama de la novela se puede sintetizar en los problemas matrimoniales enfrentados por una mujer de parte de un esposo que, con sus tendencias paranoicas, le hace la vida imposible con sus constantes celos. 
El esposo se encuentra en un estado de desconfianza permanente hacia su esposa, quien no ha dado motivo para los desplantes de su marido, pero este abusa de ella física y psicológicamente. La historia no tiene un final feliz para la pareja, pero sí para la narradora, quien después de años de angustia matrimonial, se sobrepone a todos los obstáculos presentados por su marido y sale avante sin él.

El siguiente fragmento no pertenece a "Invocación al dolor", y no forma propiamente parte del texto sobre las desventuras de la narradora y "El"; es un segmento desligado, similar al principio del Quijote, en el que se narra la aparición de un texto:

\begin{abstract}
Cuando hicimos el hoyo para plantar el rosal blanco, al pié del laurel grande, que está junto a la fuente, fué (sic) cuando encontré el cofre de metal con este manuscrito, que hoy publico, por si aparece el dueño y quiere completar estas notas, que pudieran servir de aclaración, a muchos casos en que aun se confunde, al malvado, con el irresponsable; por si pudiera ser, bandera noble (23).
\end{abstract}

Este texto "perdido", en principio, confunde al lector, ya que después de "Invocación al dolor", nos encontramos con este fragmento, cuyo origen y dueño son desconocidos para la narradora. Al concluir este texto, leemos: "A manera de título, el manuscrito empezaba con esta palabra escrita en color rojo, no sé si con tinta o con sangre: "El"..." (23). Después de dicho fragmento, el lector se encuentra con aún otro texto, que de igual forma desorienta al lector: se nos relata que la narradora enseñó a su confesor y a un magistrado algunas cuartillas donde reseñaba su noche de bodas; éstos le recomendaron no publicar aquello. En última instancia, ella le lleva estas hojas al médico que asistió a su nacimiento y es éste quien le aconseja publicarlas. Ella, después de este consejo, escribe:

Pero releí las cuartillas y haciendo más caso del Magistrado y del Cura que del Médico, las rompí en pedazos y durante un momento vi volar la historia de infamia y locura, de mi noche de bodas... (24).

La novela empieza, propiamente, con un breve fragmento indicado con tres estrellas al principio. En adelante, cada uno de los fragmentos o capítulos indica el comienzo de cada cápsula narrativa por medio de la misma indicación. La película, por su parte, mantiene hasta cierto grado el énfasis en la segmentación y fragmentación de la novela. Emilio García Riera aporta una acertada sinopsis del argumento de la película que aquí incluimos:

Francisco, caballero católico, se casa con Gloria, a quien ha conocido en un oficio religioso y a quien ha separado de su novio el ingeniero Raúl, amigo de él, después de invitar a ambos a una recepción. Al cabo de un tiempo, Raúl por poco atropella con su auto a Gloria, que camina perturbada por la calle. Ella cuenta a Raúl lo que le ocurre. Flashback. De luna de miel en Guanajuato, Gloria advierte los celos paranoicos de Francisco, que intenta incluso herir con una aguja el ojo de un conocido de ella, Ricardo, a quien supone espiando por una cerradura. Francisco provoca a Ricardo a golpes y logra que el gerente del hotel le dé la razón. Ya en México, Francisco tiene celos del joven licenciado Beltrán, a quien contrata para resolver un viejo e irresoluble litigio por unas tierras de Guanajuato. Pese a que encierra a Gloria con llave y la golpea, Francisco hace que le den la razón tanto la madre de ella, doña Esperanza, como el cura Velasco, confesor espiritual de él. Francisco provoca en Gloria un colapso al dispararle balas de salva e intenta arrojarla de lo alto de un campanario. Fin del flashback. Gloria se rebela a Francisco, que la insulta al verla bajar del auto de Raúl, pero intenta ayudarlo en la frustrada redacción a máquina de una carta para resolver lo de las tierras. Después de lograr que ella le confiese su conversación con Raúl, Francisco va al lecho donde Gloria duerme con lo "necesario" para coserle el sexo. Ella despierta y grita despavorida mientras Francisco escapa. Como Gloria deja la casa, Francisco, al buscarla, supone en falso hallarla en la iglesia donde Velasco oficia una misa y, alucinando, cree ver que todos se ríen de él, aun el cura, a quien intenta estrangular. Años después, Gloria y Raúl, casados y con un hijo que quizá es de Francisco, visitan el monasterio colombiano donde el paranoico lleva una vida de monje en apariencia tranquila (Historia documental del cine mexicano: 1951-1952, Tomo 6, 284, énfasis textual). 
Es interesante notar que García Riera utiliza continuamente el pronombre personal "él”, ya que esta es una alusión bastante clara al texto de Pinto y, al igual que en la novela, los personajes centrales son solamente dos: él y ella, es decir, Francisco y Gloria en la película.

\subsection{Personajes}

En la novela, como ya hemos avanzado, los personajes primordiales son la narradora y "El”. Cada uno de ellos lleva en sí características de su personalidad que los hace chocar una y otra vez. En nuestra sección "Secuencias principales", se explicitarán varias escenas de la novela y de la película que son vitales para la comprensión de cada uno de los personajes.

En la novela, por ejemplo, es bastante claro que la narradora sufre de un complejo de mártir, como se distingue a continuación, cuando la narradora extiende un vocablo amistoso a su dolor, junto con más imágenes gráficas de lo que le acaece:

\footnotetext{
Tú, dolor amigo, me has despertado violentamente de mi plácido sueño juvenil, para poner ante mí en las sordas negruras de la noche, cuadros de mil violencia y de furor; y con detenimiento de privilegio has hecho nudos, y heridas y sutiles desgarraduras en aquellas telitas de mi corazón, las más delicadas, las más queridas y por lo tanto las más dolorosas de tocar...(21).
}

"El” en la novela y Francisco Galván en la película son el centro de la narración. Desde el inicio de la película, Francisco es en apariencia un hombre normal, católico, de buen porte y buenos modales que se enamora de una mujer que conoció en una iglesia. Pero, conforme avanza la trama, y después de su boda con Gloria, experimenta lo que Fernando Cesarman, en El ojo de Buñuel: Psicoanálisis desde una butaca, codifica como "una desintegración psicológica, progresiva a medida que su relación heterosexual se intensifica" $(131)^{7}$. El pronóstico de Cesarman, aunque nunca con un soporte crítico, es, en primera instancia, acertado:

\footnotetext{
Enloquece científicamente: se trata de una persona con todas las características potenciales para sufrir, bajo situaciones de presión adecuadas, el cuadro de locura denominado paranoia. Además de otros elementos persecutorios, sufre crisis de celos patológicos que lo conducen a deformar la realidad entre delirios y alucinaciones. Desde el enfoque surrealista, pudiera considerarse la enfermedad de Francisco como la búsqueda de su realidad interior (131-2).
}

Cesarman da su teoría sobre lo que tal vez conforma esa vida interior: "Francisco tiene muchos rasgos en su conducta que sugieren un problema homosexual crónico y frágilmente controlado: sus relaciones con mujeres han sido mínimas y más estables con los hombres" (132). La realidad interior a la cual alude Cesarman ha sido también aproximada en estudios como el de García Riera, quien no acusa a Francisco de homosexual propiamente como lo hace Cesarman, pero advierte la actitud amistosa e íntima que tiene con su sirviente (Historia documental del cine mexicano: 1951-1952, Tomo 6, 288). Francisco siente más confianza con él que con Gloria y varias veces actúa a favor del sirviente, como cuando éste último se propasa con una mucama; Francisco la despide a ella y no a él. En otra ocasión, al discutir con Gloria, Francisco le pide al sirviente que permanezca como testigo mientras él y Gloria discuten algo muy personal que no le incumbe al sirviente. Esta actitud misógina puede dar a entender que Francisco es un homosexual reprimido. 


\subsection{Temas}

Creemos que el tema primordial de la película y de la novela es ya bastante claro por todo lo que hemos anticipado: l' amour fou. Este tipo de amor produce en el personaje masculino principal de ambos textos, celos que crean varios episodios melodramáticos para la narradora en la novela y para Gloria en la película.

Aclaremos que el tema de la novela no es del todo nuevo, ya que la historia de la literatura universal tiene varios ejemplos de textos en los cuales este tema es central durante el desarrollo de la historia. También en la historia de la literatura española, el esposo celoso ya había aparecido en El celoso extremeño (1613) y El viejo celoso (1615) de Cervantes; en El mayor monstruo, los celos (1637) y El médico de su honra (1637) de Calderón de la Barca; El hombre de mundo (1845) de Ventura de la Vega; Locura de amor (1855), La bola de nieve (1856), y Un drama nuevo (1867) de Manuel Tamayo y Baus; y La familia de León Roch (1878), Tormento (1884), y Fortunata y Jacinta (1886-7), todas del también nacido en las Islas Canarias, Benito Pérez Galdós

Aparte del amour fou y los celos, la locura de Francisco es otro tema central en ambos textos, algo que también ya era común en la literatura, desde la locura en El ingenioso hidalgo Don Quijote de la Mancha $(1605,1616)$ y El licenciado Vidriera de Cervantes (1613); Los locos de Valencia (1620) de Lope de Vega; Gloria (1877) y Fortunata y Jacinta de Galdós; El hijo de don Juan (1892) y El loco de Dios (1900) de José Echegaray; La casa de Aizgorri (1900) de Pío Baroja; Nada menos que todo un hombre (1920) de Unamuno; Visiones de neurastenia (1923) de Wenceslao Fernández Florez; Locura y muerte de nadie (1929) de Benjamín Jarnes; Los tres locos del mundo (1930) de Jacinto Grau Ramón; La hiperestésica (1934) de Gómez de la Serna; Nosotros los muertos (Relato del loco Basilio) (1948) de Manuel Sánchez Camargo; El loco (1953) de Miguel Delibes; La gota de Mercurio (1954) de Alejandro Nuñez Alonso; Las cartas boca abajo (1957) y El tragaluz (1967) de Antonio Buero Vallejo; La ira de la noche (1970) y Eterna memoria (1975) de Ramón Hernández; Las tapias (1968) de Antonio Martínez Menchen; Luz de memoria (1976) de Lourdes Ortiz; La maraña de los cien hilos (1976) de Rosa Roma; Los renglones torcidos de Dios (1976) de Torcuato Luca de Tena; El misterio de la cripta embrujada (1979) de Eduardo Mendoza; Nuevo auto de fe (1980) de Gabriel García Badell; Los fantasmas de mi cerebro (1958) y Cita en el cementerio (1983) de José María Gironella; y, como último título tentativo, El mecanógrafo (1989) de Javier García Sánchez.

La mujer, como narradora o como personaje principal, también se ha visto en innumerables obras literarias, desde Emilia Pardo Bazán y Los Pazos de Ulloa (1880), Viaje de novios (1881), La prueba (1890), Doña Milagros (1894), Memorias de un solterón (1896), y La Quimera (1905); La pródiga (1882) de Pedro Antonio de Alarcón; La espuma (1891), Maximina (1899), y La aldea perdida (1909) de Armando Palacio Valdés; La esfinge maragata (1914) de Concha Espina; la trilogía de Elena Soriano, Mujer y hombre (1955-1984); Miguel Delibes y su Cinco horas con Mario (1966); Crónica del desamor (1979) de Rosa Montero; Retahílas (1974) y El cuarto de atrás (1978) de Carmen Martín Gaite; El mismo mar de todos los veranos (1978), Varada tras el último naufragio (1980), y Para no volver (1985) de Esther Tusquets, por mencionar algunos textos.

Por otra parte, en el filme también hay otros temas/presencias constantes: el calzado y la mirada, el silencio, el simbolismo de las puertas y la distancia. 
En esta primera instancia hay que notar ya la atención al calzado y a los pies; una instancia de metonimia ya presentada anteriormente por Ávila Dueñas. Esta metonimia o fetiche de Buñuel también ha aparecido en Nazarín, Bella de día y otros filmes, y ya antes de Él en La edad de oro y El gran calavera. Buñuel tenía afinidad por los pies y en Él hay tres secuencias centradas alrededor de zapatos y pies: la primera, al principio del filme, cuando Francisco participa en el lavado de pies en su iglesia, el cual es una tradicional representación de la acción de Cristo. Francisco atiende a su amigo y confidente, el cura, y le lleva agua en el contenedor. El cura lava, seca y besa los pies de los monaguillos. Francisco es testigo de este acto una y otra vez, para después perder su mirada en los pies de los feligreses y, a través de un Point of View — el punto de vista cinematográfico de Francisco-, revisar cada uno de los que están en la primera fila hasta detenerse en los que más le gustan. La cámara hace un tilt hacia arriba y nos muestra la luminosa, radiante y bella faz de Gloria. Francisco le clava la mirada, ella se la encuentra y hacen un contacto visual; pero pronto Francisco se entretiene con su labor de llevarle agua fresca al cura.

El silencio es un tema prevaleciente en el filme, como ya hemos expuesto en nuestro ensayo "Descentering Patriarchal Discourse in Buñuel and Pinto's Él". Muchas de las acciones se hacen en silencio y el diálogo se contiene. Únicamente las escenas que presentan nueva o explican vieja información contienen diálogo. A través de la película, la mirada silente prevalece. Desde la secuencia introductoria donde Francisco mira a Gloria y ella a él, se delinea la importancia de los ojos, de esta mirada. En la segunda escena en la iglesia también predomina el silencio, hasta que Francisco decide romperlo y acercársele a Gloria. En otra ocasión, cuando Gloria llega a la fiesta de Francisco, de nuevo hay un silencio entre ellos. Francisco, en vez de dirigirse a Gloria, cruza sus primeros saludos con la madre de ésta. Sólo hasta el momento en que Francisco la monopoliza, lejos de la madre y del prometido de ella, cruzan palabras. Después de la cena, en el jardín, se besan.

Un tema conectado al silencio es también el de la privacidad. En el filme, las puertas son un tema de privacidad. Hay un abrir y cerrar constante de puertas. Esto representa el acto del habla. A veces las puertas están cerradas y otras es el mismo Francisco quien se (auto) censura o (auto) clausura, silenciándose en su encierro. El símbolo de la puerta, según Cirlot, es un símbolo femenino que "contains all the implications of the symbolic hole, since it is the door which gives access to the hole" (85). Es interesante notar que el tema del abrir y cerrar de puertas no es exclusivo de esta película de Buñuel, ya que en Ensayo de un crimen, otra de sus películas un tanto abandonadas, Archibaldo de la Cruz —el personaje masculino principal- también abre y cierra puertas desde el instante en que aparece en pantalla. En su introducción, aparece como un chiquillo jugando al escondite en un ropero. Cuando su institutriz abre la puerta de este ropero, el niño aún se mantiene tras la ropa escondido. "Archi”, como le llama su madre, abre y cierra constantemente la puerta de su pequeña caja de música mecánica y, en ese sentido, pronuncia, habla. Archibaldo también está en constante silencio. Es económico con sus palabras, lacónico. Abre y cierra las puertas de su casa, de sus habitaciones, manteniendo su privacidad y alejado de sus sirvientes. Hay un deseo de no identificarse con la clase baja, con la servidumbre.

Lo anterior nos lleva al siguiente tema, la distancia. Francisco, distante de todo, frío, no es afín para participar en actividades populares en lugares abiertos; prefiere los lugares cerrados, el anonimato: "Prefiero el cine a las carreras. Polvo, calor y, sobre todo, gente despreocupada. Me hace daño la felicidad de los tontos". En una secuencia importante del filme, la 
distancia entre Francisco y la gente común y corriente que él visualiza desde la torre de la iglesia le permite ofrecer su diatriba en contra de la humanidad; él, con gala de superioridad, apunta la inferioridad que percibe en otros:

\footnotetext{
Ahí tienes a tu gente, desde aquí se ve claro lo que son, gusanos arrastrándose por el suelo. Dan ganas de aplastarlos con el pie. El egoísmo es la esencia de un alma noble. Yo desprecio a los hombres, entiendes; si fuera Dios no los perdonaría nunca.
}

Por otra parte, una discusión simbólica no entra del todo en las apreciaciones de Paranaguá. En su comentario de la primera secuencia, Paranaguá olvida la función de mención avanzada que tiene la campana, aparte del simbolismo que una campana tiene según él. En $A$ Dictionary of Symbols de J. E. Cirlot, se exponen connotaciones de poder asociadas con su sonido y, como es un objeto que está en el aire, tiene un significado místico, una conexión entre el cielo y la tierra (24).

En $E ́ l$, encontramos que la campana no es el único objeto cargado de simbolismo apropiado para nuestra discusión, ya que el constante abrir y cerrar de las puertas de la casa de Francisco puede dar a entender ese acceso al hoyo que escribe Fuentes. En resumidas cuentas, Francisco, al abrirlas, busca ese pasaje sexual que también pueda simbolizar su incipiente sexualidad, ya que, según se ha discutido, es bastante reconocida su castidad, ya perdida con Gloria. Por otra parte, el cerrarlas no sólo simboliza su deseo de no comunicarse o de aislarse, sino también de no permitir a nadie entrar en ese pasaje sexual y metafórico representado por la puerta. Dicho de otra forma, este abrir y cerrar de puertas puede simbolizar su preferencia sexual ya aproximada por Cesarman: una homosexualidad encubierta, pero delatadora en múltiples ocasiones, evidenciadas a través de la trayectoria diegética de la película, pero que será conveniente explorar en otra ocasión.

\subsection{Estilo}

La novela Él está caracterizada por un claro discurso psicótico, el cual se define desde el inicio por el uso de adjetivos relacionados con la locura. El sufrimiento y el dolor mental que ha experimentado y se le ha impuesto a la narradora crea la necesidad de producir una realidad mental que, dada su incoherencia y confusión, de alguna forma captura lo absurdo de su propia realidad. De acuerdo con Tzvetan Todorov, el discurso psicótico

\footnotetext{
se definit par une défaillance du processus de référence. Cette défaillance peut s'originer dans les divers éléments du processus: les mots, les choses ou le rapport entre les deux; ce qui produit trois variétes de discours pyschotique correspondant a la catatonie, la paranoia el la schizophrénie (49).
}

Los términos y adjetivos relacionados con manicomios, esquizofrenia y locura se evidencian constantemente, pero la narradora duda de si es real o si su locura es fingida. Aún cuando lo encierran en el manicomio, ella recibe "enhorabuenas" por el pronto restablecimiento del enfermo y se encuentra con la familia del marido que quiere sacarlo de su encierro (155).

La naturaleza turbia de "El" en su relación con el mundo exterior se manifiesta, lógicamente, en su forma de comunicación con este mundo y sus habitantes. En toda la novela, el protagonista se compara constantemente con Dios y advierte de su absoluta superioridad a todos. El control que maneja "El" sobre la narradora es también claro. De cierta forma, en el 
texto, la narradora intenta mantener cierta autoridad e individualidad cuando utiliza la primera persona. El número de fragmentos donde se aprecia textualmente esto es considerable. Escribe la narradora: "me preguntaba yo continuamente" (25), "me dijo 'El' (26), "me nombró", "mis menores movimientos" (27), "pensé" (27), "me dijo enfurecido" (28), "Y vi con espanto, en la habitación contigua"(28), "Yo escuchaba desorientada" (29), "los amigos repetíanme" (29), "le pregunté" (30), "yo veía que de un momento a otro" (31), "me había dicho" (31), "yo creí que era delirio y debí perder el sentido por completo porque no oí más... Sólo sé que al día siguiente me visitó el médico de abordo y como Él estaba delante, no pude hablarle" (31), "Yo en cambio me" (55), y "Y yo callaba" (64). Es clara la distancia del esposo, su tormentor, también con "obtuvo ciertamente un triunfo en su carrera" (29), "Él cayó en un estado de desesperación" (30), y "su orgullo" (41). Estos pronombres posesivos y personales demuestran la clara distancia entre los dos, aún cuando la narradora también hace uso del plural en primera persona: "nos miraban" (28) y "nuestra casa" (29), los cuales son algunos ejemplos de aquellos breves instantes en los que su unión con el esposo es clara.

Hay que notar que, al final de cada episodio o fragmento, las últimas palabras escritas no advierten un hálito de esperanza, mas sí la desesperanza, el pesimismo del ambiente repleto de infelicidad que se vive en ese hogar: "Él odiaba" (40), "Que huía, lo atormentaba cruelmente" (41), "Si no quieres que me vuelva loco, insúltame, grita, rabia, y verás como al castigarte con "razón para ello", me quedo descansado y tranquilo..."(43), "¡la que se moría de frío era yo!!"(45). El ambiente familiar es pesado y turbio por las tendencias paranoicas y violentas de "El". La muerte hace constante acto de presencia en la narración. La hermana de la narradora muere, "El" amenaza con matar a aquellos que lo molesten, ya sea humano, animal o un miembro de la familia, y, en cierto punto de la novela, la narradora teme por la vida de sus hijos.

La narradora desconfía del medio, de la escritura, ya que no advierte que ofrezca una liberación segura: “¿Llegará hasta las almas este mi dolor? ¿Se hará tangible este martirio como los otros donde hay violencia y sangre...?” (48).

\subsection{Secuencias principales}

La Iglesia católica juega un papel importante en la novela y en la película y es el escenario de escenas importantes en la segunda. Como ya hemos referido, cuando la narradora pidió la opinión de su confesor, este le pidió que guardara sus cuartillas. El filme, al igual que la novela, también nos presenta una iglesia que, sin saberlo en primera instancia, será testigo de la persecución sentimental de Francisco hacia Gloria, el deterioro mental de éste y su eventual enclaustramiento.

La primera secuencia del filme, situada en una iglesia, nos sirve de introducción a los personajes centrales: Francisco y Gloria. La cámara nos presenta lo que ocurre desde tres puntos de vista: el espectador, Francisco y Gloria. En el filme, encontramos otras dos escenas en la iglesia: cuando Francisco, por instinto, va a la iglesia a buscar a Gloria, de quien se ha enamorado, y cuando Francisco, persiguiendo un coche en el que piensa que va Gloria, termina en la misma iglesia y tiene un episodio paranoico-esquizofrénico que presenta el clímax de la película. Esta iglesia, según Víctor Fuentes, está cargada de "connotaciones simbólicas de vientre materno y vagina dentada" (Los mundos de Buñuel: 93) y, según Cesarman, es un "recinto de la represión sexual" (El ojo de Buñuel: Psicoanálisis desde una butaca: 141). 
Los episodios paranoicos de Francisco son múltiples y no versan únicamente en situarse en la iglesia. A través de la trayectoria narrativa del filme, vemos que Francisco sufre trastornos al estar de vacaciones, en un hotel, en un tren, al estar en su tierra natal (Guanajuato), en la capital de México (D.F.), en casa, cenando o hasta en un campanario.

En un tren, mientras viaja al destino de su luna de miel, empiezan a destellar para Gloria las primeras instancias de la incipiente paranoia de Francisco. Después de implorarle y exigirle información sobre el pasado de Gloria, Francisco, como un niño, la insulta al no recibir las respuestas que buscaba. Instantes después, Francisco se nota arrepentido e invoca las disculpas de Gloria. En otra ocasión, después de un altercado, tienen la siguiente conversación:

Francisco: Me odias, ¿verdad?, me aborreces. Sí, eres muy desgraciada conmigo, no me lo niegues. Ten lástima de mí, nadie más desgraciado que yo. Estoy solo, únicamente te tengo a ti y me odias.

Gloria: No te odio Francisco, sé que no tienes la culpa de lo que haces y sufres más que yo.

La interacción entre Francisco y Gloria se deteriora dada la paranoia enfermiza del primero:

Francisco: Gloria, Gloria, dime la verdad, la duda amargaría mi vida. Yo te juro que olvidaré todo, no te lo reprocharé. Todo lo que tú me cuentes. Háblame como si fuera un confesor, soy tu marido.

Gloria: Te suplico que no sigas, no hay nada en mi vida que pueda avergonzarme.

Francisco: Entonces te niegas a contármelo. ¿No comprendes que con tu actitud equívoca aumentas mis dudas?

Gloria: Por favor, Francisco.

Francisco: Está bien, calla tu pasado, si quieres, que yo lo conoceré algún día.

Francisco, en ocasiones, como ya hemos dicho, y en varios puntos de la película, aparenta ser una persona normal al estar en el exterior; pero, en otras, el caso es totalmente lo contrario. En una secuencia crítica, Francisco y Gloria cenan, el ambiente es tenso y rápidamente se deteriora al punto de que terminan en un disgusto, gritándose el uno al otro. Gloria prefiere que el mayordomo no escuche, pero Francisco le pide que no se vaya, pues encuentra más confianza en su criado que en su propia esposa.

Hay una secuencia importante, la cual críticos han asumido como un posible acto de castración, pero se debe clarificar que, en nuestra opinión, la aguja y el hilo podrían ser utilizadas para coserle la boca a Gloria. La navaja se utiliza para cortar el hilo. Fuentes y Cesarman han discutido lo simbólico de esta escena: el primero, usando la definición de Klossowski, lo llama "esteta de la bizarría sexual", en esta secuencia "homenaje-parodia de Sade" (Buñuel en México: 121, énfasis textual); el segundo, citando a Sade en la última lección de Philosophie dans le boudoir, acierta que el amor fou de Francisco ha fluctuado "hasta el odio enfermizo" al decidir coser sus orificios, castigándola con el "equivalente femenino de la castración masculina” (140). 
El episodio clímax de la iglesia, en donde Francisco pierde totalmente el contacto con la realidad, es sumamente interesante por la yuxtaposición de los puntos de vista utilizados. En una toma desde el supuesto punto de vista de Francisco, podemos ver a los miembros de la iglesia actuando normalmente, para inmediatamente verlos en otra burlándose de Francisco. En otras tomas, vemos al monaguillo haciendo su tarea con el cura para después, con el cambio mental de Francisco, abrir los ojos con sus dedos para dar a entender "¡Yo los vi!"; el mismo cura de la iglesia se ve dirigiendo su misa, para momentos después burlarse de nuestro paranoico protagonista, quien explota a gritos: “¡Lo saben! ¡Lo saben todo!”. En la iglesia, al sentirse el hazmerreír de todos los presentes, Francisco exclama: "Dios mío, ya lo saben; ya lo saben todos. Se están burlando de mí". Él, sintiéndose el centro de las burlas, ataca al cura e intenta ahorcarlo. Sobre esto, Cesarman escribe que Francisco:

\footnotetext{
En el sacerdote ve al padre castrado en apariencia, pero también al padre que lo ha engañado al tener una vida sexual con su esposa. Al agredir al sacerdote, Francisco trata de encontrar la salvación buscando destruir, desde el exterior, una serie de valores que él siente que han destruido su vida (El ojo de Buñuel: Psicoanálisis desde una butaca: 141-2).
}

Después de una elipsis, en la que transcurren varios años, se nos reintroduce a Gloria y a Luis, quienes van acompañados de un niño llamado Francisco. Estos visitan un convento para inquirir sobre la condición de Francisco. Instantes antes de concluir la película, después de que Gloria y Raúl dejan el convento, se produce la siguiente y tan curiosa interacción:

Francisco: Ya ve usted, padre, cómo yo no estaba tan perturbado como decían. El tiempo se ha encargado de darme un poco la razón. En fin, murió el pasado, aquí encontré la verdadera paz del alma.

Padre Prior: Siga usted con su lectura piadosa, siga.

Irónicamente, la imagen final de Francisco es totalmente opuesta a la aparente tranquilidad y beatería que demuestra frente al Padre Prior: Francisco, en el jardín del convento, se aleja de la cámara, caminando en un zigzag reconocido por los expertos como un claro ejemplo de que Francisco está curado aparentemente, pero en resumidas cuentas no es así.

\section{Conclusión}

En este ensayo, se ha presentado el tema del enamorado enfermo de celos, llámesele Amour fou o lo que el lector prefiera, en ambos textos, literario y cinematográfico. Este tema es universal en el drama, la poesía, la literatura y el cine. Ya hemos discutido de acusaciones de celos y paranoia apuntadas a Buñuel, que brotan una y otra vez en filmes distintos.

En conclusión, después de presentar una introducción que enmarca este ensayo y un trasfondo histórico y crítico de ambos textos - hecho necesario para poder contextualizar el lugar que ocupa no sólo la novela, sino también la película en el mundo literario y cinematográfico-, nuestro análisis se ha enfocado en el estudio del texto literario y cinematográfico mediante el estudio de la estructura, la trama, los personajes, los temas y el estilo, así como también de las secuencias principales para terminar este somero estudio comparativo. 


\section{Notas}

1. Hay que notar que, al iniciarse esta investigación, las fuentes informativas sobre Mercedes Pinto eran pocas, ya fuera en biblioteca o en internet. Hoy, al hacer una búsqueda por el ciberespacio, esta es una pequeña muestra de las páginas conectadas a ella:

http://www.filmfestivals.com/sansebas/sfilme3.htm

http://www.grancanariacultura.com/hemeroteca/mpinto/biografia.htm

http://www.grancanariacultura.com/hemeroteca/mpinto/

http://80.81.104.134/entrevistas/gustavorojo/

2. Televisa S.A. de C.V. es dueña de la Editorial Televisa y, por consiguiente, de esta revista.

3. En el ensayo de Nieves Pérez Riego, se presenta información que difiere notablemente por la ofrecida en Somos. Pérez Riego advierte que el primer esposo de Mercedes Pinto no fue un Duque, y que era sólo un "respetado catedrático, capitán de la marina mercante y paranoico" (69). No es nuestro propósito aquí revisar dónde se presenta la verdad, pero tal vez valga la pena aclarar que Somos es una revista publicada por Televisa, compañía en la que los hijos de la señora Pinto, Rubén y Gustavo Rojo, han trabajado fielmente durante muchos años. Fácil es entonces llegar a la conclusión de que el acceso a información pertinente que reporteros de Somos tuvieron fue tal vez de más importancia que el familiar distante con quien se pudo entrevistar Pérez Riego. Sea como fuere, Somos y Emilio García Riera en su Historia documental del cine mexicano son las dos fuentes que se refieren al esposo de Pinto como "El Duque de Foronda".

4. Este libro ha causado una polémica en España y ha suscitado todo tipo de comentarios alrededor del autor, quien también es un médico forense. El libro expone la condición de la mujer en España que, aún después de recibir maltratos del esposo y avergonzarse, lo disculpan con la explicación de que no es algo fuera de lo normal.

5. Este evento histórico para la psicología ha sido foco temático de conferencias, la más reciente llevada a cabo en Argentina.

6. Los flashbacks no son una creación del séptimo arte, ya que son mecanismos literarios pero adaptados al cine (From Story to Movie to Critique: 146).

7. Arturo Ripstein, director mexicano de Profundo carmesí, La viuda negra, La ilegal, y otros filmes, fue discípulo de Buñuel. Por eso, es interesante ver las semejanzas entre el Francisco de Él y Gabriel Lima en El castillo de la pureza. Éste último personaje es también un paranoico que odia a los hombres y se compara constantemente con Dios. Lima también sufre una desintegración psicológica que termina con su libertad. Para más información, ver nuestro ensayo "Gods and Monsters: Mexican Patriarchy in Luis Spota's La carcajada del gato and Arturo Ripstein's El castillo de la pureza”. Publicado en Tropos, Vol. XXVIII, Spring 2002. Pp. 22-31.

\section{Bibliografía}

Ávila Dueñas, Iván Humberto. 1994. El cine mexicano de Luis Buñuel: Estudio analítico de los argumentos y personajes. México: Dirección General de Publicaciones del Consejo Nacional para la Cultura y las Artes Instituto Mexicano de Cinematografía.

Buñuel, Luis. 1982. Mi último suspiro. Barcelona: Plaza \& Janes Editores.

2002. Él. 1953. DVD. Divisa. 
2002. Ensayo de un crimen. 1955. DVD. Divisa.

Cesarman, Fernando. 1998. El Ojo de Buñuel: Psicoanálisis desde una butaca. México: Miguel Ángel Porrúa.

Cirlot, J.E. 1991. A Dictionary of Symbols. New York: Dorset Press.

Colina, José de la y Tomás Pérez. 1993. Turrent. Buñuel por Buñuel. Madrid: Plot Ediciones.

Cummings, Gerardo. 2002. "Gods and Monsters: Mexican Patriarchy in Luis Spota’s La carcajada del gato and Arturo Ripstein's El castillo de la pureza". Tropos XXVIII (Spring): 22-31.

Fuentes, Víctor. 1993. Buñuel en México: Iluminaciones sobre una pantalla pobre. Teruel: Instituto de Estudios Turolenses.

2000. Los mundos de Buñuel. Madrid: Akal.

García, Gustavo y Rafael Aviña. 1997. Época de oro del cine mexicano. México: Editorial Clío.

García Riera, Emilio. 1993. Historia documental del cine mexicano: 1951-1952. Guadalajara: Universidad de Guadalajara.

Moscowitz, John E. 1999. From Story to Movie to Critique: The Ties Between Fiction and Film. MA: Simon and Schuster Custom Publishing.

Quinlan, David. 1999. Quinlan's Film Directors. London: B.T. Batsford Ltd.

Paranaguá, Paulo Antonio. 1997. Arturo Ripstein. Madrid: Ediciones Cátedra.

2001. Él: Luis Buñuel. Barcelona: Ediciones Paidós.

Pérez Riego, Nieves. 1998. “Él, de Mercedes Pinto: Vanguardia y paranoia.” Quaderni Ibero-Americani: Attualita Culturale della Penisola Iberica e America Latina. 83-84: 69-79.

Pinto, Mercedes. 1989. El. Islas Canarias, España: Viceconsejería de Cultura y Deportes del gobierno autonómico de Canarias.

Rubio Gribble, Susana. 1992. Del texto literario al texto fílmico: representación del punto de vista narrativo en tres adaptaciones del cine español de los ochenta. Tesis doctoral: State University of New York at Stony Brook. 
Spencer, Sharon. 1971. Space, Time and Structure in the Modern Novel. Chicago: The Swallow Press Inc.

Todorov, Tzvetan. 1976. “Le Discours psychotique.” L'Analyse du discours. Quebec: Centre Educatif et Culturel Inc.

Zúñiga, Félix y Héctor Argente. 2001. “Mercedes Pinto: Poetisa de espíritu rebelde.” Somos. Año 12 (210): 6-11. 